\title{
Prevotella timonensis sp. nov., isolated from a human breast abscess
}

\author{
Olga O. Glazunova, ${ }^{1}$ Thierry Launay, ${ }^{2}$ Didier Raoult ${ }^{1}$ and Véronique Roux ${ }^{1}$ \\ ${ }^{1}$ Laboratoire de Bactériologie-Virologie, Hôpital de la Timone, CNRS UMR 6020, IFR48, \\ 264 rue Saint-Pierre, 13385 Marseille Cedex 05, France \\ ${ }^{2}$ Service de Chirurgie Générale, Clinique Vert-Coteau, 41 rue Brandis, 13005 Marseille, France
}

Correspondence

Véronique Roux

vroux91@hotmail.com

\begin{abstract}
Gram-negative anaerobic rods were isolated from a human breast abscess. Based on genotypic and phenotypic characteristics, the novel strain belonged to the genus Prevotella. Phylogenetic analysis based on $16 \mathrm{~S}$ rRNA gene sequence comparisons showed that it was closely related to Prevotella buccalis (94\% 16S rRNA gene sequence similarity), Prevotella salivae (90\%) and Prevotella oris $(89.1 \%)$. The major cellular fatty acid was $\mathrm{C}_{14: 0}(19.5 \%)$. The new isolate represents a novel species in the genus Prevotella, for which the name Prevotella timonensis sp. nov. is proposed. The type strain is strain $4401737^{\top}\left(=\operatorname{CIP} 108522^{\top}=\right.$ CCUG $\left.^{50105^{\top}}\right)$.
\end{abstract}

The creation of the genus Prevotella was proposed by Shah \& Collins (1990) to characterize 'the moderately saccharolytic, predominantly oral Bacteroides species'. Identification at the species level among this group of obligatory anaerobic Gram-negative rods remains problematic due to the lack of characteristic phenotypic and biochemical traits. 16S rRNA gene sequence analysis has improved this situation and the number of recognized Prevotella species has increased over the last few years. Prevotella pallens (Kononen et al., 1998), Prevotella shahii, Prevotella salivae and Prevotella multiformis (Sakamoto et al., 2004, 2005), Prevotella marshii and Prevotella baroniae (Downes et al., 2005) have been described recently. Prevotella species have been isolated from the oral cavity, the upper respiratory tract and the urogenital tract in humans. Some species, such as Prevotella ruminicola and the closely related species Prevotella brevis, Prevotella bryantii and Prevotella albensis, have been recovered from the rumen and hindgut of many mammalian species (Avgustin et al., 1997). Species of the genus Prevotella are considered to be part of the normal flora, but sometimes they can induce disease. Thus, bacteraemia and sepsis caused by representatives of the genus Prevotella have led to liver and spleen abscesses (Brook \& Frazier, 1998), appendix abscess (Paneri et al., 2002), cervical abscess, meningitis (Frat et al., 2004) and have also provoked endocarditis in an immunocompromised patient (Dominguez-Castellano et al., 2001). Recently, Prevotella intermedia and Prevotella nigrescens were characterized by specific 16S rRNA gene PCR amplification from artery samples of patients suffering from vascular disease (Fiehn et al., 2005; Iwai et al., 2005). DNA of Prevotella species was PCR amplified and identified after cloning from samples of endodontic infections (Rolph

The GenBank/EMBL/DDBJ accession number for the 16S rRNA gene sequence of Prevotella timonensis strain $4401737^{\top}$ is DQ518919. et al., 2001) and from the bacterial microbiota in the human stomach (Bik et al., 2006). Genomic identification of these bacteria will allow a better understanding of their involvement in pathology.

In this report, we describe a novel species belonging to the genus Prevotella isolated from a human breast abscess.

A 40-year-old woman underwent breast abscess puncture. Blood sample analysis revealed anaemia (haemoglobin, $109 \mathrm{~g} \mathrm{l}^{-1}$ ) and the erythrocyte sedimentation rate was recorded as $32 \mathrm{~mm} \mathrm{~h}^{-1}$. Liquid from the punctured abscess was cultured and two different Gram-negative bacteria were isolated. The first isolate was identified as Prevotella disiens using API 20A strips (bioMérieux). However, a doubtful identification was obtained for the second isolate, strain $4401737^{\mathrm{T}}$. $16 \mathrm{~S}$ rRNA gene sequence determination was performed. This confirmed that strain $4401737^{\mathrm{T}}$ was a member of the genus Prevotella and was possibly a representative of a novel species. The antimicrobial susceptibility of strain $4401737^{\mathrm{T}}$ was determined according to the National Committee for Clinical Laboratory Standards (NCCLS) criteria. Strain $4401737^{\mathrm{T}}$ showed intermediate susceptibility to penicillin G, but was susceptible to Augmentin, cefotetan, imipenem, metronidazole and vancomycin $\left(30 \mu \mathrm{g} \mathrm{ml}^{-1}\right)$.

Surface colonies on sheep blood agar (bioMérieux) were circular, white-greyish, smooth, shiny, non-pigmented and 1-2 $\mathrm{mm}$ in diameter after $72 \mathrm{~h}$. Growth and haemolytic activity were tested at $37^{\circ} \mathrm{C}$ on Columbia agar with $5 \%$ sheep blood. Growth was tested in anaerobic and microaerophilic atmospheres which were created using GENbag anaer and GENbag microaer incubation systems (bioMérieux), respectively. Growth was also tested in the presence of air or $5 \% \mathrm{CO}_{2}$. Growth was tested at different temperatures $\left(25,30,37\right.$ and $\left.45^{\circ} \mathrm{C}\right)$. Optimum growth of 
strain $4401737^{\mathrm{T}}$ was obtained at $37^{\circ} \mathrm{C}$, but growth occurred between 25 and $37^{\circ} \mathrm{C}$. Strain $4401737^{\mathrm{T}}$ was strictly anaerobic and non-haemolytic.

The size and ultrastructure of cells of the novel strain were determined by transmission electron microscopy (TEM). Cells were grown in liquid trypticase soy broth (TSB; Becton Dickinson) medium for $48 \mathrm{~h}$, collected by pipetting and stained with $1 \%(\mathrm{w} / \mathrm{v})$ phosphotungstic acid. Samples were examined on an electron microscope (Morgagni 268D; Philips) at an operating voltage of $60 \mathrm{kV}$. The rods were $0.8-1.4 \mu \mathrm{m}$ long and $0.3-0.5 \mu \mathrm{m}$ wide and usually occurred singly.

Catalase activity was negative as determined by the ID colour catalase test kit (bioMérieux). Bile resistance was tested by growing the bacteria on peptone/yeast extract/ glucose agar plates supplemented with $2 \%(\mathrm{w} / \mathrm{v})$ dehydrated gall salt (bile sac powder; MP Biomedicals) equivalent to $20 \%(\mathrm{v} / \mathrm{v})$ bile. Antibiotic resistance to $5 \mu \mathrm{g}$ vancomycin $\mathrm{ml}^{-1}, 1000 \mu \mathrm{g}$ kanamycin $\mathrm{ml}^{-1}$ and $10 \mu \mathrm{g}$ colistin $\mathrm{ml}^{-1}$ was tested in thioglycollate with resazurin broth (bioMérieux). An anaerobic atmosphere was created by the addition of $2 \mathrm{ml}$ paraffin oil. Strain $4401737^{\mathrm{T}}$ was bile sensitive and resistant to vancomycin, colistin and kanamycin.

Commercially available API 20A, rapid API $32 \mathrm{~A}$ and API $50 \mathrm{CH}$ strips (bioMérieux) were used to characterize the biochemical properties of strain $4401737^{\mathrm{T}}$ according to the manufacturer's instructions. Incubation was performed at $37^{\circ} \mathrm{C}$. The results of these tests are given in the species description. The phenotypic characteristics of strain $4401737^{\mathrm{T}}$ were compared with those of Prevotella buccalis ATCC $35310^{\mathrm{T}}$, P. shahii EHS $11^{\mathrm{T}}$ and Prevotella oralis ATCC $33269^{\mathrm{T}}$ which were identified as the most closely related species to strain $4401737^{\mathrm{T}}$ when $16 \mathrm{~S}$ rRNA gene sequences were analysed. The results are presented in Table 1.
Preparation and determination of cellular fatty acids were carried out by following the procedures given for the Sherlock Microbial Identification System (MIDI). The fatty acid content of strain $4401737^{\mathrm{T}}$ was significantly different to that of other members of the genus Prevotella. The predominant cellular fatty acids were $\mathrm{C}_{14: 0}(19.5 \%), \mathrm{C}_{16: 0}$ $(15.3 \%)$, iso- $\mathrm{C}_{14: 0}(14 \%)$ and $\mathrm{C}_{18: 2} \omega 6,9 c / \mathrm{C}_{18: 0}$ (16\%; fatty acids could not be separated by the MIDI system). It has been reported previously that the major fatty acids in the genus Prevotella are anteiso- $\mathrm{C}_{15: 0}$, iso- $\mathrm{C}_{15: 0}$, iso- $\mathrm{C}_{17: 0}$ 3-OH, $\mathrm{C}_{16: 0}$ and $\mathrm{C}_{18: 1} \omega 9 c$ (Moore et al., 1994; Sakamoto et al., 2004). The presence of $\mathrm{C}_{18: 2} \omega 6,9 c$ and the absence of iso- $\mathrm{C}_{17: 0} 3-\mathrm{OH}$ which were noted for our novel isolate are not usual features for species of the genus Prevotella. However, unexpected fatty acid contents have already been reported for other representatives of the genus Prevotella (Sakamoto et al., 2004; Willems \& Collins, 1995).

Bacterial DNA was extracted using the FastDNA Kit (BIO 101; Illkirch) as recommended by the manufacturer. PCR amplification of the 16S rRNA gene was performed using the universal primer pair $\mathrm{fD} 1$ and $\mathrm{rp} 2$ (Weisburg et al., 1991). PCR products were purified using MultiScreen PCR (Millipore) and sequencing reactions were carried out using a DNA sequencing kit (BigDye Terminator Cycle Sequencing v2.0 Ready Reactions; PE Biosystems) according to the manufacturer's instructions. Sequencing products were purified and electrophoresis was performed with a 3100 Genetic Analyzer (Applied Biosystems). The sequences obtained for strain $4401737^{\mathrm{T}}$ were compared with sequences deposited in the GenBank database by using the BLAST program through the NCBI server. Gene sequences were aligned using the multisequence alignment program CLUSTAL_X (1.8). Phylogenetic relationships with closely related species were determined by using MEGA version 2.1 (Kumar et al., 2001). Distance matrices were determined following the assumptions described by Kimura (1980) and were used to elaborate the dendrogram using the neighbour-

Table 1. Differential characteristics of $P$. timonensis sp. nov. and related Prevotella species

Strains: 1, strain $4401737^{\mathrm{T}}$; 2, P. buccalis ATCC $35310^{\mathrm{T}} ; 3$, P. shahii $\mathrm{EHS}_{1}{ }^{\mathrm{T}}$ (data from Sakamoto et al., 2004); 4, P. oralis ATCC $33269^{\mathrm{T}}$ (Holdeman et al., 1984). None of the strains produce pigment. + , Positive; -, negative; W, weakly positive; ND, not determined.

\begin{tabular}{|lcccc|}
\hline Characteristic & $\mathbf{1}$ & $\mathbf{2}$ & $\mathbf{3}$ & $\mathbf{4}$ \\
\hline Aesculin hydrolysis & $\mathrm{W}$ & + & - & + \\
$\alpha$-Galactosidase & $\mathrm{W}$ & + & $\mathrm{W}$ & $\mathrm{ND}$ \\
$\beta$-Glucosidase & - & + & - & $\mathrm{ND}$ \\
Fermentation of: & & & + & + \\
$\quad$ Mannose & - & + & + & + \\
$\quad$ Raffinose & - & + & - & $\mathrm{ND}$ \\
Arginine arylamidase & + & + & $\mathrm{ND}$ \\
Glutamyl glutamic acid arylamidase & $\mathrm{C}_{14: 0}, \mathrm{C}_{16: 0}$, & $\mathrm{ND}$ & $\mathrm{C}_{18: 1} \omega 9 c$, & $\mathrm{ND}$ \\
Major cellular fatty acids & $\mathrm{C}_{18: 2} \omega 6,9 c / \mathrm{C}_{18: 0}$ & & $\mathrm{C}_{16: 0}, \mathrm{C}_{16: 0} 3-\mathrm{OH}$ & \\
& & &
\end{tabular}




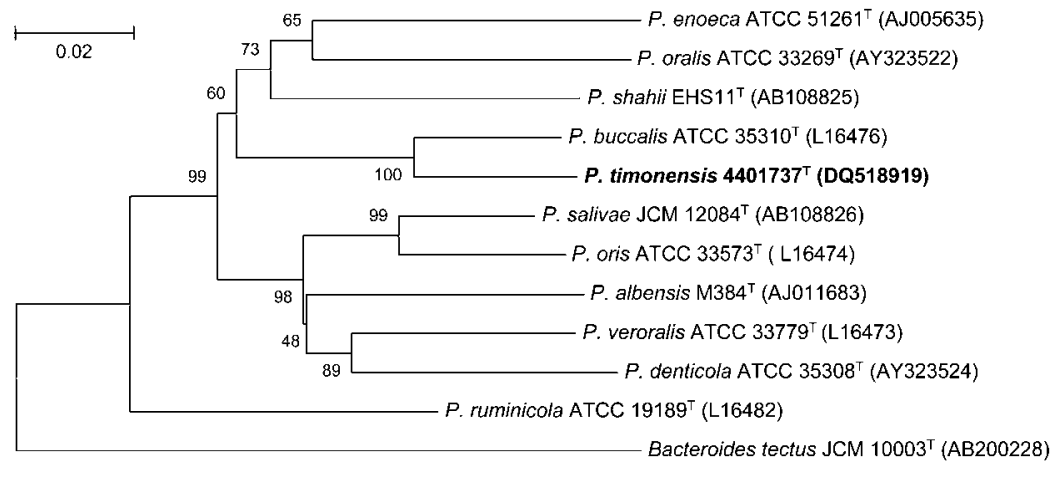

Fig. 1. Phylogenetic tree of representatives of the genus Prevotella inferred from 16S rRNA gene sequence comparisons (1451 nt fragment). Numbers at nodes are the proportions of 100 resamplings that support the topology shown. Bacteroides tectus JCM $10003^{\top}$ was used as the outgroup. Bar, 0.02 nucleotide changes per nucleotide position. joining method (Saitou \& Nei, 1987). The maximumparsimony algorithm was also used to infer phylogenetic relationships. A bootstrap analysis (bootstrap values were obtained for a consensus tree based on 100 randomly generated trees) was performed to investigate the stability of the trees obtained. The tree topology was the same with both methods. Phylogenetic analysis demonstrated that strain $4401737^{\mathrm{T}}$ is a member of the genus Prevotella (Fig. 1). Strain $4401737^{\mathrm{T}}$ was closely related to $P$. buccalis (94\% 16S rRNA gene sequence similarity), $P$. salivae $(90 \%)$ and $P$. oris $(89.1 \%)$. These percentages of similarity were low $(<97 \%)$, confirming that strain $4401737^{\mathrm{T}}$ represents a novel species.

Based on the results described above, we propose that strain $4401737^{\mathrm{T}}$ represents a novel species, Prevotella timonensis sp. nov.

\section{Description of Prevotella timonensis sp. nov.}

Prevotella timonensis (ti.mo.n.en'sis. N.L. fem. adj. timonensis from the name Hôpital de la Timone, the hospital in Marseille, France, from where the type strain was isolated).

Cells are obligately anaerobic, non-pigmented, non-sporeforming, non-motile, Gram-negative straight rods. Growth occurs on sheep blood agar and in TSB liquid medium. Growth is inhibited by $20 \%$ (w/v) bile. After $72 \mathrm{~h}$ growth on blood sheep agar, surface colonies are circular, whitegreyish, smooth, shiny and up to $1-2 \mathrm{~mm}$ in diameter. Temperature range for growth is $25-37^{\circ} \mathrm{C}$, with an optimum at $37^{\circ} \mathrm{C}$. After $48 \mathrm{~h}$ growth in TSB medium, rods are $0.8-1.4 \mu \mathrm{m}$ in length, $0.3-0.5 \mu \mathrm{m}$ in diameter and occur singly (as observed by TEM). Catalase-negative. Ferments glucose, lactose and maltose. Tests positive for gelatin hydrolysis using an API 20A strip. With an API 20A strip, tests negative for indole formation, urease activity, aesculin hydrolysis and fermentation of mannitol, sucrose, salicin, xylose, arabinose, glycerol, cellobiose, mannose, melezitose, raffinose, sorbitol, rhamnose and trehalose. Using API ID 32A tests, positive for activities of alkaline phosphatase, $\beta$-galactosidase, $\alpha$-glucosidase, $N$-acetyl- $\beta$ glucosaminidase, $\alpha$-fucosidase, arginine arylamidase, leucyl glycine arylamidase and alanine arylamidase. Activities of $\beta$-galactosidase 6 -phosphate and $\alpha$-galactosidase are weakly positive. Negative reaction for indole production, reduction of nitrates and fermentation of mannose and raffinose. No activity is detected for glutamic acid decarboxylase, arginine dihydrolase, $\beta$-glucosidase, $\alpha$-arabinosidase, $\beta$-glucuronidase, proline arylamidase, phenylalanine arylamidase, leucine arylamidase, pyroglutamic acid arylamidase, tyrosine arylamidase, glycine arylamidase, histidine arylamidase, glutamyl glutamic acid arylamidase or serine arylamidase. Using an API 50CH strip, only reactions for D-ribose, D-tagatose, potassium 5-ketogluconate and aesculin (iron citrate) are positive after 1 week of cultivation. The fatty acid profile is characterized by the predominance of $\mathrm{C}_{14: 0}(19.5 \%)$, followed by $\mathrm{C}_{16: 0}(15.3 \%)$, iso- $\mathrm{C}_{14: 0}(14 \%)$ and a mixture of $\mathrm{C}_{18: 2} \omega 6,9 \mathrm{c}$ and $\mathrm{C}_{18: 0}$ $(16 \%)$.

The type strain, $4401737^{\mathrm{T}} \quad\left(=\mathrm{CIP} \quad 108522^{\mathrm{T}}=\mathrm{CCUG}\right.$ $\left.50105^{\mathrm{T}}\right)$, was isolated from a human breast abscess.

\section{Acknowledgements}

We are grateful to Bernard Campagna for his technical assistance in electronic microscopy and to Kent Molin (University of Göteborg, Sweden) for his technical assistance with the cellular fatty acid composition.

\section{References}

Avgustin, G., Wallace, R. J. \& Flint, H. J. (1997). Phenotypic diversity among ruminal isolates of Prevotella ruminicola: proposal of Prevotella brevis sp. nov., Prevotella bryantii sp. nov., and Prevotella albensis sp. nov. and redefinition of Prevotella ruminicola. Int J Syst Bacteriol 47, 284-288.

Bik, E. M., Eckburg, P. B., Gill, S. R., Nelson, K. E., Purdom, E. A., Francois, F., Perez-Perez, G., Blaser, M. J. \& Relman, D. A. (2006). Molecular analysis of the bacterial microbiota in the human stomach. Proc Natl Acad Sci U S A 103, 732-737.

Brook, I. \& Frazier, E. H. (1998). Microbiology of liver and spleen abscesses. J Med Microbiol 47, 1075-1080.

Dominguez-Castellano, A., Angel, M. M., Jose, R.-V. M., GarciaIglesias, M., Rodriguez-Bano, J., Galvez, J. \& Perez-Cano, R. (2001). Prevotella denticola endocarditis in an intravenous drug abuser. Enferm Infecc Microbiol Clin 19, 280-281.

Downes, J., Sutcliffe, I., Tanner, A. C. \& Wade, W. G. (2005). Prevotella marshii sp. nov. and Prevotella baroniae sp. nov., isolated from the human oral cavity. Int J Syst Evol Microbiol 55, 1551-1555. 
Fiehn, N. E., Larsen, T., Christiansen, N., Holmstrup, P. \& Schroeder, T. V. (2005). Identification of periodontal pathogens in atherosclerotic vessels. J Periodontol 76, 731-736.

Frat, J. P., Godet, C., Grollier, G., Blanc, J. L. \& Robert, R. (2004). Cervical spinal epidural abscess and meningitis due to Prevotella oris and Peptostreptococcus micros after retropharyngeal surgery. Intensive Care Med 30, 1695.

Holdeman, L. V., Keller, R. W. \& Moore, W. E. C. (1984). Genus I. Bacteroides Castellani and Chalmers 1919, 959 ${ }^{\mathrm{AL}}$. In Bergey's Manual of Systematic Bacteriology, vol. 1, pp. 604-631. Edited by N. R. Krieg \& J. G. Holt. Baltimore, MD: Williams \& Wilkins.

Iwai, T., Inoue, Y., Umeda, M., Huang, Y., Kurihara, N., Koike, M. \& Ishikawa, I. (2005). Oral bacteria in the occluded arteries of patients with Buerger disease. J Vasc Surg 42, 107-115.

Kimura, M. (1980). A simple method for estimating evolutionary rates of base substitutions through comparative studies of nucleotide sequences. J Mol Evol 16, 111-120.

Kononen, E., Eerola, E., Frandsen, E. V., Jalava, J., Matto, J., Salmenlinna, S. \& Jousimies-Somer, H. (1998). Phylogenetic characterization and proposal of a new pigmented species to the genus Prevotella: Prevotella pallens sp. nov. Int J Syst Bacteriol 48, 47-51.

Kumar, S., Tamura, K., Jakobsen, I. B. \& Nei, M. (2001). MEGA2: molecular evolutionary genetics analysis software. Bioinformatics 17, 1244-1245.

Moore, L. V., Bourne, D. M. \& Moore, W. E. (1994). Comparative distribution and taxonomic value of cellular fatty acids in thirty-three genera of anaerobic gram-negative bacilli. Int J Syst Bacteriol 44, 338-347.
Paneri, G., Prince-Zucchelli, M. A., Masseboeuf, H. \& Timpone, G. (2002). Portal vein thrombosis and Prevotella melanigenica revealing an appendicular abscess. Presse Med 31, 603-606.

Rolph, H. J., Lennon, A., Riggio, M. P., Saunders, W. P., MacKenzie, D., Coldero, L. \& Bagg, J. (2001). Molecular identification of microorganisms from endodontic infections. J Clin Microbiol 39, $3282-3289$.

Saitou, N. \& Nei, M. (1987). The neighbor-joining method: a new method for reconstructing phylogenetic trees. Mol Biol Evol 4, 406-425.

Sakamoto, M., Suzuki, M., Huang, Y., Umeda, M., Ishikawa, I. \& Benno, Y. (2004). Prevotella shahii sp. nov. and Prevotella salivae sp. nov., isolated from the human oral cavity. Int J Syst Evol Microbiol 54, 877-883.

Sakamoto, M., Huang, Y., Umeda, M., Ishikawa, I. \& Benno, Y. (2005). Prevotella multiformis sp. nov., isolated from human subgingival plaque. Int J Syst Evol Microbiol 55, 815-819.

Shah, H. N. \& Collins, D. M. (1990). Prevotella, a new genus to include Bacteroides melaninogenicus and related species formerly classified in the genus Bacteroides. Int J Syst Bacteriol 40, 205-208.

Weisburg, W. G., Barns, S. M., Pelletier, D. A. \& Lane, D. J. (1991) $16 \mathrm{~S}$ ribosomal DNA amplification for phylogenetic study. J Bacteriol 173, 697-703.

Willems, A. \& Collins, M. D. (1995). 16S rRNA gene similarities indicate that Hallella seregens (Moore and Moore) and Mitsuokella dentalis (Haapsalo et al.) are genealogically highly related and are members of the genus Prevotella: emended description of the genus Prevotella (Shah and Collins) and description of Prevotella dentalis comb. nov. Int J Syst Bacteriol 45, 832-836. 